\title{
A mathematical model for ammonia solar and synthesis reactors
}

\author{
Ramadan Ali Abdiwe* and Markus Haider
}

\begin{abstract}
The thermochemical system using ammonia as energy storage carrier is investigated in this study. A mathematical model was developed to predict the behavior of both reactors in the ammonia-based closed-loop system. For the importance of the dissociation and formation process in the system, the model focused only on the solar and the synthesis reactors. The study shows that maintaining the best mass flow rate is important for achieving the maximum ammonia dissociation and formation processes and as a result the maximum thermal output. Operating the reactors at higher pressure than suggested increases the formation of ammonia at the synthesis; however, it lowers the thermal output of the system.
\end{abstract}

Keywords: Ammonia dissociation, Ammonia formation, Heat recovery

\section{Background}

One of the major obstacles of utilizing solar energy is storing that energy when it is not needed to be used in the absence of the sun. The thermochemical concept seems to offer an attractive solution to this problem. Thermochemical conversion of solar energy into chemical fuels offers an efficient path for long-term storage and long-range transport of solar energy (Steinfeld and Meiers 2004).

A unique concept of storing solar energy thermochemically was investigated at the Australia National University (ANU) theoretically and experimentally. Figure 1 shows a schematic of ammonia dissociation, storage, and synthesis system. In this concept, the ammonia is used as a heat transfer fluid at the solar receiver side and as a product at the synthesis reactor side, and the steam required for electricity generation can be produced from the heat recovery process at the synthesis.

As shown in the figure, the reactants pass through endothermic and exothermic reactors, where the dissociation and the formation of the ammonia take place, respectively. In between the reactors, there is a storage

\footnotetext{
*Correspondence: rabdiwe@ite.tuwien.ac.at Institute for Energy Systems and Thermodynamics, Vienna University of Technology, Getreidemarkt 9, 1060 Vienna, Austria
}

container (vessel), and the vessel is attached to counterflow heat exchangers between ingoing and outgoing reactors. The ammonia is dissociated and formed according to the reversible reaction.

$$
\mathrm{NH}_{3}+\mathrm{dH} \leftrightarrow 0.5 \mathrm{~N}_{2}+1.5 \mathrm{H}_{2}
$$

The ammonia had been studied as energy carrier in CSP technologies only in the last two decades; therefore, few papers were published in this topic. In 1995 Luzzi concluded that dish-based solar thermal systems, which incorporate the ammonia-based closed-loop thermochemical energy storage and transport technology, are technically viable using commercially available system components (Luzzi and Lovegrove 1995). In 1998 Kreetz carried out an exergy analysis of a semi-realistic 30-MPa isobaric system, and his exergy analysis revealed that the major irreversibilities occur within the exothermic reactor and the counterflow heat exchanger between ingoing and outgoing reactors (Kreetz and Lovegrove 2002). In 2003 Lovegrove completed an experimental solar-driven ammonia-based closed-loop thermochemical energy storage system, and the system used a cavity receiver containing 20 reactor tubes filled with iron-based catalyst material. Lovegrove concluded that ammonia dissociation receiver/reactors are well suited for operation through solar transients and ammonia synthesis heat 


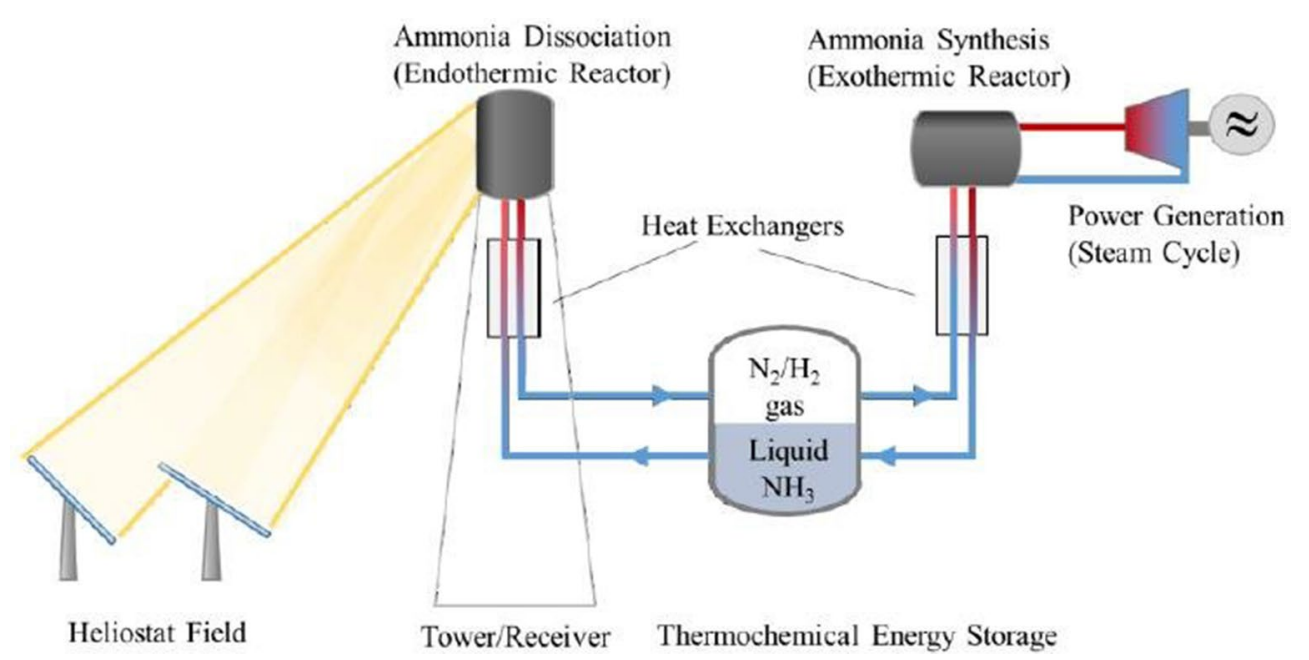

Fig. 1 Schematic of ammonia dissociation, storage, and synthesis system (Chen and Aryafar 2015)

recovery reactors are capable of stable, predictable operation with heat recovery at temperatures suitable for highquality superheated steam production. However, using such system in large-scale power plants might be a challenging not only from the design point of view but also from the parameters that ensure the maximum possible efficiency. Therefore, the optimal parameters such as mass flow rate and pressure of the whole system are of great interest.

In this paper, a mathematical model was developed for solar and synthesis reactors to predict the behavior of the reaction process inside both reactors with respect to the mass flow rate and the constant pressure. It should be mentioned that the ammonia dissociation and formation processes may contain several numbers of reactors; however, the model is designed for one tubular solar reactor and one tubular synthesis reactor.

\section{Physical model}

The ammonia is dissociated endothermically by absorbing the solar energy at the solar reactor in the cavity receiver during the daytime to hydrogen and nitrogen according to Eq. (1); the hot reactants will pass through the reactor's catalyst bed toward the vessel after exchanging their thermal energy in a counterflow heat exchanger with the liquid ammonia. The temperature inside the vessel is above the ambient temperature saturation pressure of ammonia, and therefore, the ammonia will be condensed in the bottom of the vessel and the nitrogen and hydrogen stay at the top. The nitrogen and hydrogen mixture leave the vessel and react exothermically at standard ammonia synthesis to produce ammonia providing thermal energy for superheated steam production.
As the case in the dissociation loop, the reactants in the formation loop must be heated up at a counterflow heat exchanger with the formed ammonia before them getting to the synthesis. The system works at a constant pressure, and therefore, an expander and a compressor are added to the vessel to control and regulate the pressure. In order for the reaction to occur during the dissociation and the formation stages, packed bed reactors are used with standard commercial catalyst material.

The geometry of the cavity receiver is assumed to have a cylindrical shape with a little base in the bottom to hold a bundle of solar reactors organized in a way that allows equal distribution of the solar flux between them. Figure 2 shows a schematic design of the cavity receiver with a bundle of solar reactors attached to it.

The solar and synthesis reactors are both assumed to be tubular geometry type. Figure 3 shows a longitudinal cut of both reactors. The tubular reactor is filled up with a catalyst to allow the reaction process to occur.

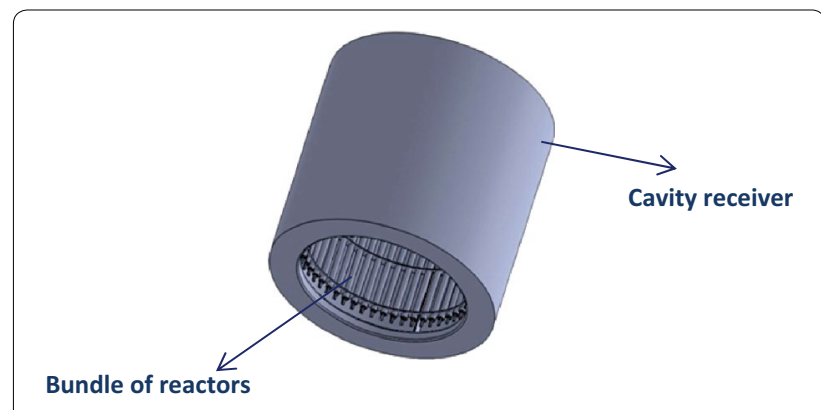

Fig. 2 A schematic design of the solar reactor 


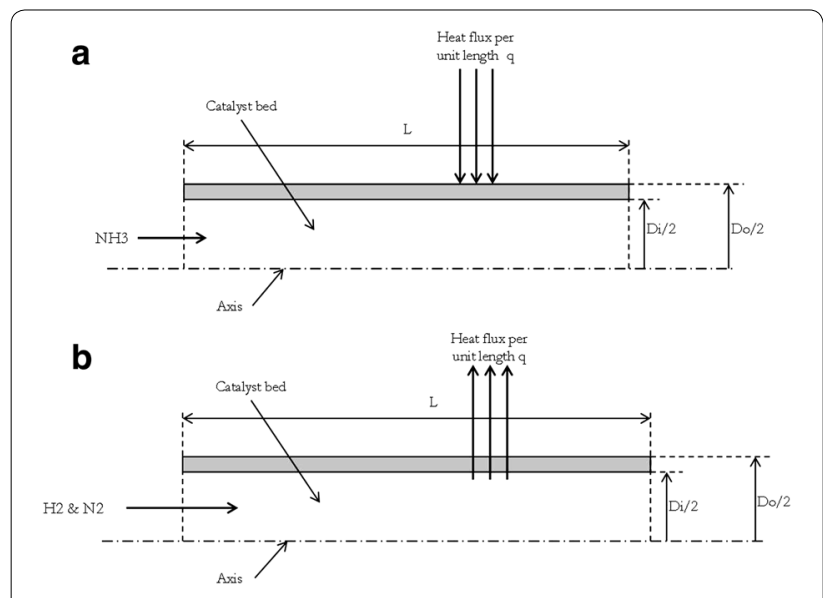

Fig. 3 A skittish of the tubular $\mathbf{a}$ solar reactor geometry and $\mathbf{b}$ synthesis reactor geometry

The physical parameters of the cavity receiver, ammonia solar reactor, ammonia synthesis reactor, and the catalyst bed are provided in Table 1 .

The standard commercial catalyst material used as a backed bed in both reactors is iron-cobalt catalyst. Table 2 shows the properties of the catalyst.

Knowing the geometries of the cavity receiver, the heat flux on solar reactor can be calculated as shown in the equation below.

$$
\begin{aligned}
& Q_{\text {rad,cavity }}=\varepsilon_{\text {eff }} \cdot A_{\mathrm{ap}} \cdot E \\
& E=\sigma \cdot T^{4} \\
& T^{4}=\left(T_{\mathrm{ab}}^{4}-T_{\infty}^{4}\right) \\
& \varepsilon_{\mathrm{eff}}=\frac{1}{1+\left(\frac{1-\varepsilon}{\varepsilon}\right) \frac{A_{\mathrm{ap}}}{A_{\mathrm{ab}}}}
\end{aligned}
$$

\begin{tabular}{|c|c|c|}
\hline Item & Geometry type & Dimensions \\
\hline Cavity receiver & Cylinder & $\begin{array}{l}\text { Outer diameter }=4.0 \mathrm{~m} \\
\text { Inner diameter }=3.5 \mathrm{~m} \\
\text { Height }=4 \mathrm{~m}\end{array}$ \\
\hline Solar reactor & Tubular & $\begin{array}{l}\text { Outer diameter }=0.08166 \mathrm{~m} \\
\text { Inner diameter }=0.06166 \mathrm{~m} \\
\text { Length }=3 \mathrm{~m}\end{array}$ \\
\hline Synthesis reactor & Tubular & $\begin{array}{l}\text { Outer diameter }=0.1 \mathrm{~m} \\
\text { Inner diameter }=0.09 \mathrm{~m} \\
\text { Length }=4 \mathrm{~m}\end{array}$ \\
\hline Catalyst bed & Cylinder & $\begin{array}{l}\text { Diameter }=0.0052 \mathrm{~m} \\
\text { Height }=0.0050 \mathrm{~m}\end{array}$ \\
\hline
\end{tabular}

Table 1 Geometry specifications of the cavity receiver

\begin{tabular}{|c|c|}
\hline Name & Iron-cobalt \\
\hline \multirow[t]{4}{*}{ Chemical composition } & Al, wt\% 25 \\
\hline & $\mathrm{Fe}, \mathrm{wt} \% 24$ \\
\hline & Co, wt\% 24 \\
\hline & K, wt\% 21 \\
\hline \multirow[t]{2}{*}{ Impurities } & $\mathrm{S}<200 \mathrm{ppm}$ \\
\hline & $\mathrm{Cl}<50$ ppm \\
\hline \multirow[t]{3}{*}{ Physical properties } & Axial strength $\mathrm{kg} / \mathrm{cm}^{2} 400$ \\
\hline & Particle density, kg/l 2.5 \\
\hline & Filling density, kg/l 1.6 \\
\hline Activation energy & 95E+03 (J mol) \\
\hline Pre exponential factor & $1 \mathrm{E}-2\left(\mathrm{~mol} / \mathrm{s} \mathrm{cm}^{3} \mathrm{~atm}\right)$ \\
\hline
\end{tabular}
and the reactors
Table 2 Properties of the catalyst used in both reactors

$$
q=\frac{Q_{\text {rad, cavity }}}{A_{\mathrm{ab}}}
$$

In the synthesis case, the heat recovery process that is necessary to produce steam to generate electricity can be calculated thanks to the mature industry in producing ammonia.

\section{Numerical model}

For any simple combustion, where the number of possible species in the one exhaust stream matches the number of elements involved, the mass and energy balances allow predictive simulation behavior. However, in a general chemical reactor additional information is required to predict the behavior of the reaction process and this information can be provided by functional equations. Typical examples for such equations are: pressure drop prescription, definitions of separation efficiencies, conversion rates, etc. These equations express the second law of thermodynamics taking into consideration that heat will always flow from the hot to the cold side and chemical reactions always proceed toward an equilibrium state (with respect to temperature, pressure, and composition).

Several steps must be taking to implement equilibrium models such as the solar and synthesis reactors. Due to the similarity in both reactors, only the steps for the solar reactor will be explained as follows:

\section{- Defining a control volume on the reactor}

The control volume of the solar reactor is simple with one feed stream and one drain stream as shown in (Fig. 4). Both gas streams can be modeled as ideal gases.

The feed stream ideally consists of ammonia only, and the syngas product contains three species: nitrogen $\mathrm{N}_{2}$, hydrogen $\mathrm{H}_{2}$, and ammonia $\mathrm{NH}_{3}$. 


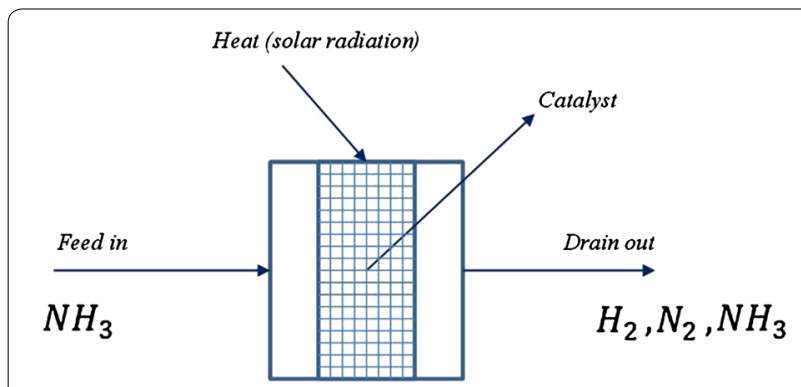

Fig. 4 A control volume of the solar reactor

- Summary of output variables attributed to determining equations

The output variables that are necessary for determining equations of the solar reactor are illustrated in Table 3.

\section{- Modeling equations}

The modeling equations can be illustrated as shown below:

- Pressure drop

$$
P_{\text {drain }}=P_{\text {feed }}-\Delta_{\mathrm{p}}
$$

- Energy balance

$$
n_{\text {drain }} \cdot H_{\text {drain }}^{*}=n_{\text {feed }} \cdot H_{\text {feed }}^{*}+Q_{\text {add }} \text {, }
$$

where

$$
H_{\mathrm{drain}}^{*}=\sum_{i} y_{i} \cdot H_{i}^{*}\left(T_{\mathrm{drain}}\right)
$$

- Sum of drain mole fractions $=1[\mathrm{~mol} / \mathrm{mol}]$

$$
Y_{\mathrm{NH}_{3}, \text { drain }}+Y_{\mathrm{H}_{2}, \text { drain }}+Y_{\mathrm{N}_{2} \text {, drain }}=1
$$

- Hydrogen balance $\left[\mathrm{mol}_{\mathrm{H} 2} / \mathrm{s}\right]$

$$
n_{\text {drain }} \cdot\left(Y_{\mathrm{H}_{2}, \text { drain }}+\frac{3}{2} Y_{\mathrm{NH}_{3}, \mathrm{drain}}\right)=n_{\text {feed }} \cdot \frac{3}{2} Y_{\mathrm{NH}_{3}, \text { feed }}
$$

\section{Table 3 Output variables}

\begin{tabular}{lll}
\hline Symbol & Description & Determining equation \\
\hline$P_{\text {drain }}$ & Pressure drain stream & Pressure drop set \\
$T_{\text {drain }}$ & Temperature at drain stream & Energy balance \\
$n_{\text {drain }}$ & Total molar flow of drain stream & Global mass balance \\
$Y_{\mathrm{NH}_{3} \text {,drain }}$ & Drain stream ammonia content & Ammonia balance \\
$Y_{\mathrm{N}_{2} \text {, drain }}$ & Drain stream nitrogen content & Nitrogen balance \\
$Y_{\mathrm{H}_{2} \text {, drain }}$ & Drain stream hydrogen & Hydrogen balance \\
\hline
\end{tabular}

- Nitrogen balance $\left[\mathrm{mol}_{\mathrm{N} 2} / \mathrm{s}\right]$

$$
n_{\text {drain }} \cdot\left(Y_{\mathrm{N}_{2} \text {,drain }}+\frac{1}{2} Y_{\mathrm{NH}_{3}, \text { drain }}\right)=n_{\text {feed }} \cdot \frac{1}{2} Y_{\mathrm{NH}_{3}, \text { feed }}
$$

- Ammonia dissociation equilibrium

$$
K_{\mathrm{P}, \mathrm{NH}_{3}}\left(T_{\text {drain }}\right)=\frac{Y_{\mathrm{N}_{2}, \text { drain }} \cdot Y_{\mathrm{H}_{2}, \text { drain }}^{3}}{Y_{\mathrm{NH}_{3}, \text { drain }}^{2}}\left(\frac{P_{\text {drain }}}{P_{\mathrm{o}}}\right)^{2}
$$

$K_{\mathrm{P}}$ is a function of temperature only and can be calculated from Gibbs free enthalpy of reaction according to:

$$
\ln \left(K_{\mathrm{P}}(T)\right)=-\frac{\Delta G_{\mathrm{R}}^{\mathrm{o}}(T)}{R \cdot T}
$$

$\Delta G_{\mathrm{R}}^{\mathrm{o}}$ is the Gibbs free enthalpy of standard pressure (1 bar) and can be calculated from the conventional enthalpies and entropies of the participating species:

$$
\Delta G_{\mathrm{R}}^{\mathrm{o}}=\sum_{i}\left[v_{i} \cdot H_{i}^{*}\left(P_{\mathrm{o}} \cdot T\right)\right]-T \cdot \sum_{i}\left[v_{i} \cdot S_{i}\left(P_{\mathrm{o}} \cdot T\right)\right]
$$

Therefore, equilibrium can be calculated directly from thermodynamic data.

\section{- Calculating strategy}

In principle, the six output variables listed in step 2 together with equations in step 3 represent a fully determined system of algebraic, nonlinear equations. To solve such a system, a numerical method must be applied (MATLAB). When solving the model, a good starting guess is required to obtain a solution and care must be taken to prevent any $Y_{i \text {,drain }}$ to get below zero at any time.

As mentioned previously, the same steps must be carried out for the synthesis reactor taking into consideration that the reactants in the solar reactor are the products in the synthesis reactor and vice versa. The system is assumed to work under steady-state operation, and the heat loss is considered to be zero. The values of the running parameters are given in Table 4.

Table 4 Simulation runs: range of parameters

\begin{tabular}{ll}
\hline Parameter & Range of operation \\
\hline Mass flow rate (in both reactors) & $20-40 \mathrm{~g} / \mathrm{s}$ \\
Pressure & $50-70 \mathrm{bar}$ \\
Solar reactor inlet gas temperature & $250^{\circ} \mathrm{C}$ \\
Synthesis reactor inlet gas temperature & $150^{\circ} \mathrm{C}$ \\
Heat flux distributed on the solar reactor & $100 \mathrm{~kW}$ \\
\hline
\end{tabular}




\section{Results}

The behavior of both reactors under steady-state operation has been predicted with the previously mentioned numerical model. An important input for the model is the heat flux distributed on the solar reactor inside the cavity which has been derived based on the geometry of the cavity receiver. The model confirmed the technical feasibility of the design concept of both reactors regardless of the simplicity which can be considered as advantage.

Figure 5 shows modeled internal reactor temperature profiles plus the corresponding reaction extent profiles for three different mass flow rates in the solar reactor. The horizontal axis shows the position along the catalyst bed as measured from the point of gas inlet. With lower mass flow rate value represented in (a), the maximum reaction rate is achieved leading to the higher internal temperature along the bed. This behavior reflects the effect of the mass flow on the dissociation process. In general terms, lower mass flow works to increase reaction rates while higher mass flow works to reduce them. Thus, maximum thermal output will be achieved by keeping the mass flow rate as low as possible and care must be taken to prevent the overheating that might occur when all the ammonia is dissociated.

In the case of the synthesis and as shown in Fig. 6, the behavior reflects the effect of mass flow rates on the heat recovery process. Lower mass flow rate works to increase the ammonia produced; however, reduces the thermal output as shown in the figures above. This means that as more ammonia is produced along the length of the reactor, temperatures need to fall to maintain the necessary 'distance' from equilibrium.

The initial increase in pressure has no impact on the reaction rate in the case of the solar reactor as shown in Fig. 7a-c. When the pressure increased from 50 to 70 bar, there was very much no change on the corresponding reaction extent profiles. The opposite can be said in the case of the synthesis reactor where the increase in the pressure leads to the increase in the reaction rate and more ammonia produced as shown in Fig. 8a-c. However, as mentioned previously more ammonia produced leads to the lower thermal output.

The results of Figs. 5, 6, 7, and 8 were based on an assumption that the gas inlet temperature was always
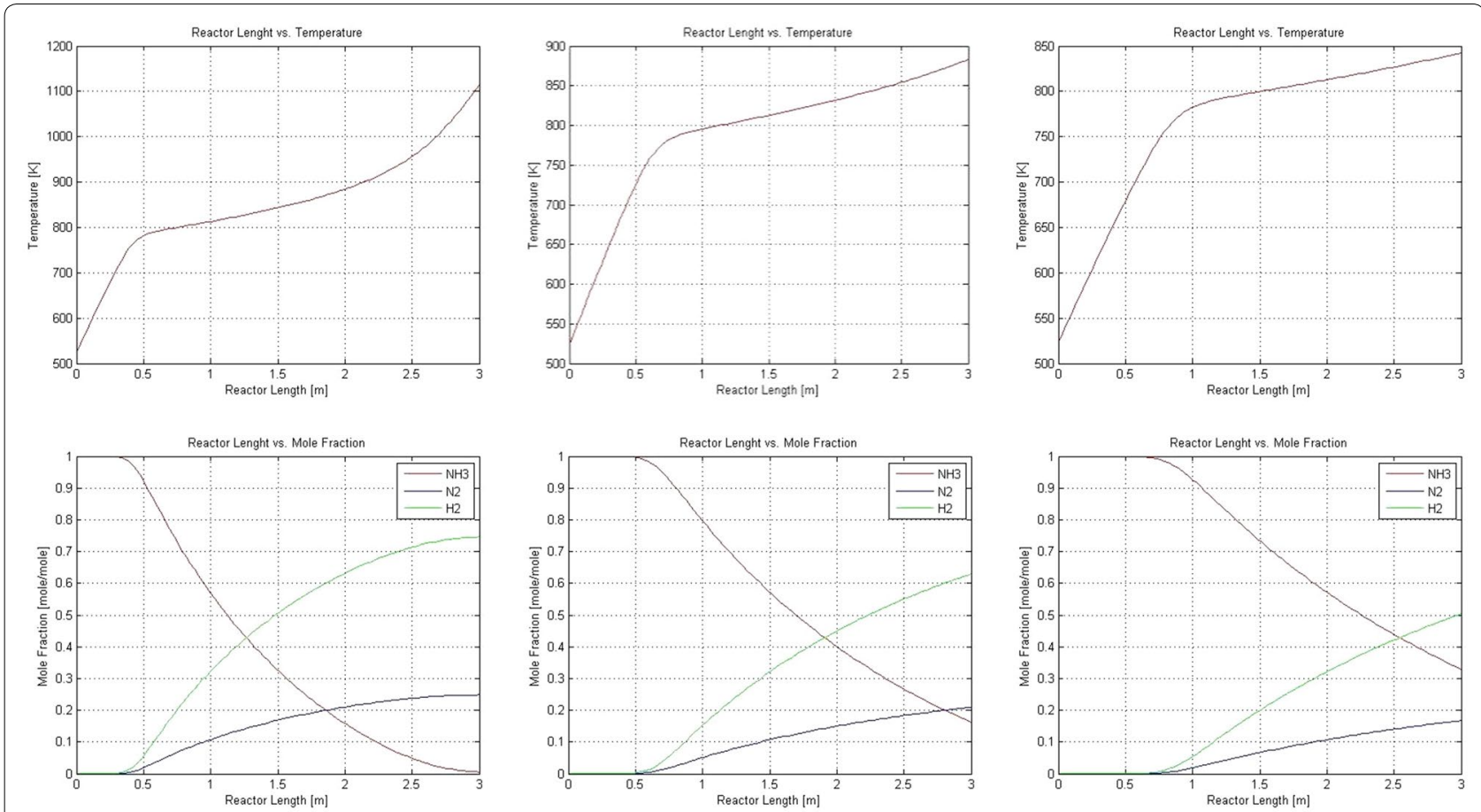

a

b

C

Fig. 5 Internal reactor temperature profiles plus the corresponding reaction extent profiles at the solar reactor for three different mass flows $\mathbf{a}$ $20 \mathrm{~g} / \mathrm{s}, \mathbf{b} 30 \mathrm{~g} / \mathrm{s}, \mathbf{c} 40 \mathrm{~g} / \mathrm{s}$ and a constant pressure $50 \mathrm{bar}$ 

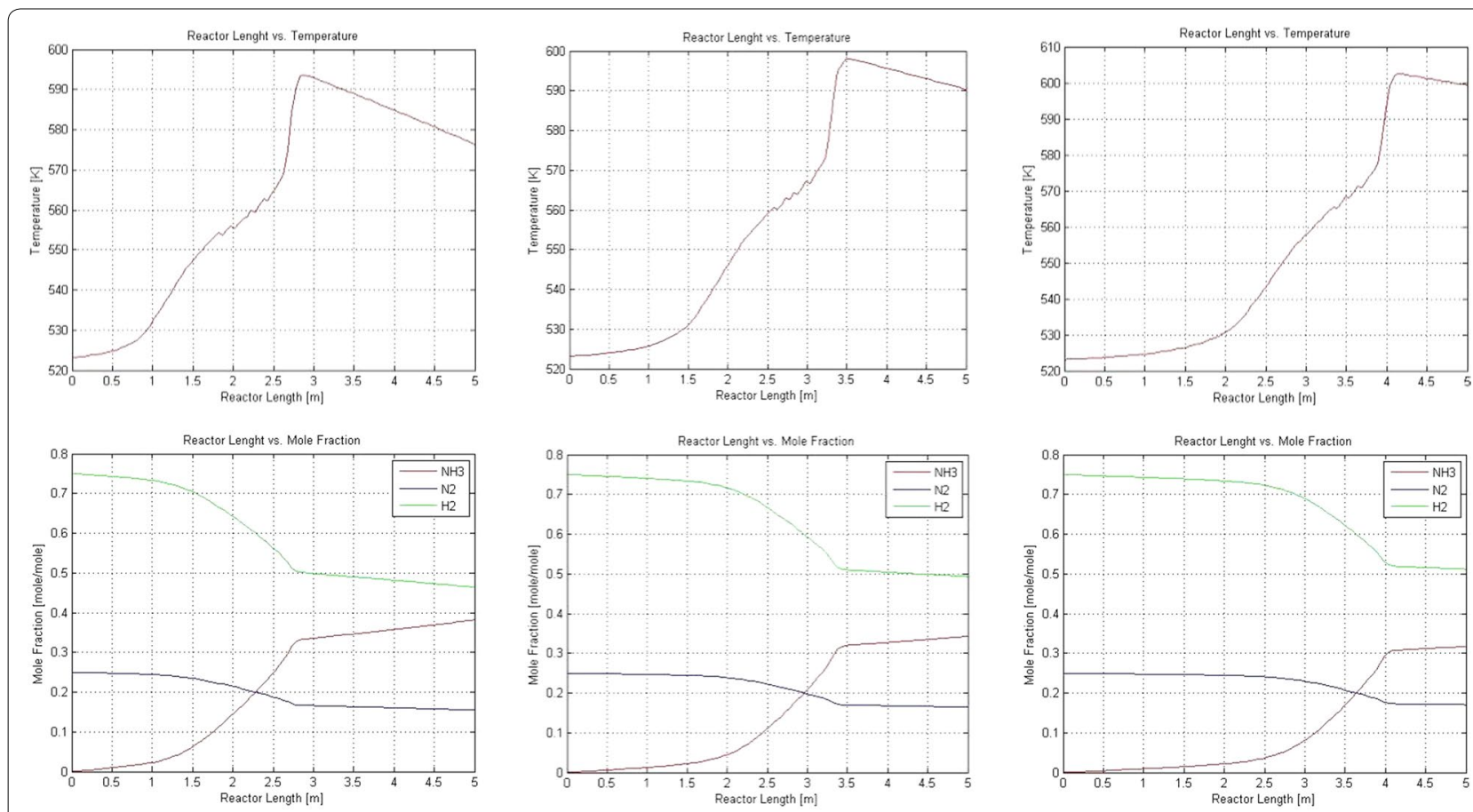

a

b

C

Fig. 6 Corresponding reaction extent profiles at the synthesis for three different mass flows a $20 \mathrm{~g} / \mathrm{s}, \mathbf{b} 30 \mathrm{~g} / \mathrm{s}, \mathbf{c} 40 \mathrm{~g} / \mathrm{s}$ and constant pressure 50 bar

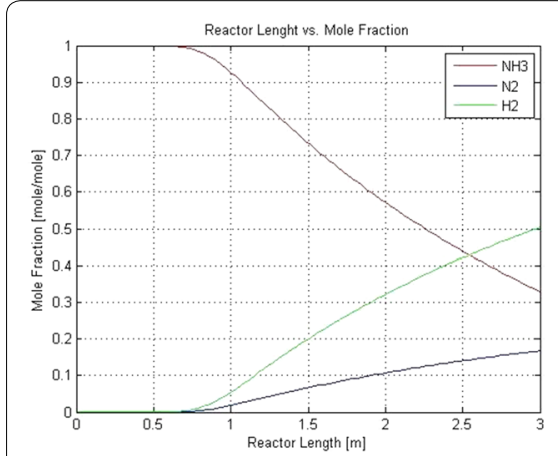

a

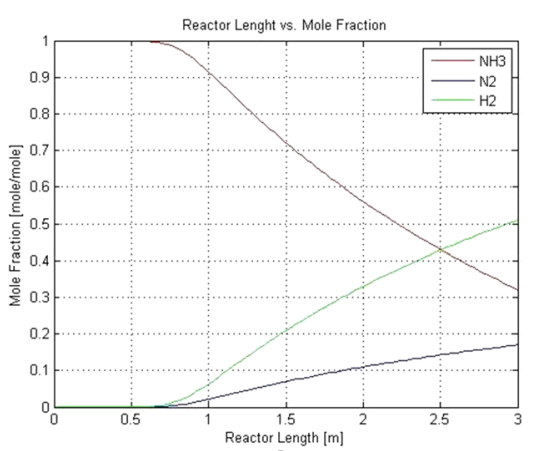

b

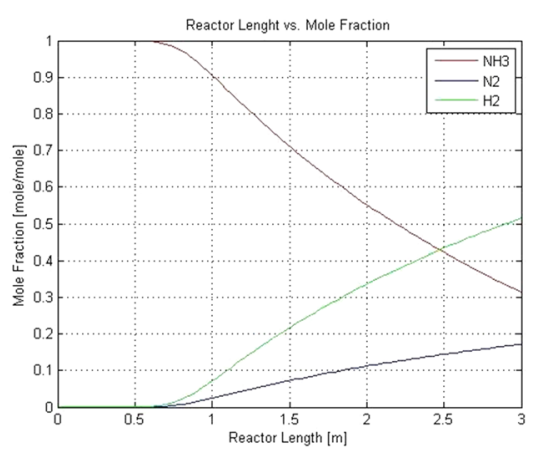

C

Fig. 7 Corresponding reaction extent profiles at the solar reactor for three different pressure values $\mathbf{a} 50 \mathrm{bar}, \mathbf{b} 60 \mathrm{bar}$, c 70 bar and constant mass flow $40 \mathrm{~g} / \mathrm{s}$ bar

$250{ }^{\circ} \mathrm{C}$ in both reactors. Even though the gas inlet temperature is another variable for getting maximum reaction rate and effective dissociation and formation of ammonia, it has been found to be of only minor influence.

\section{Conclusions}

The developed mathematical model of the tubular ammonia solar reactor and ammonia synthesis reactor represents an important step for improving the performance of ammonia solar reactor and ammonia synthesis reactor which results to an optimal design of the ammonia-based closed-loop system. The study shows that maintaining the best mass flow rate is important for achieving the maximum ammonia dissociation and formation processes and as a result the maximum thermal output of the system. The model indicates that the increase in gas inlet temperature has a minor influence on the efficiency of both reactors; furthermore, operating the system at 


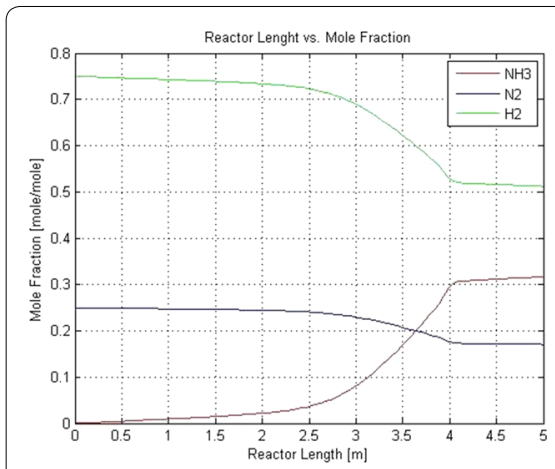

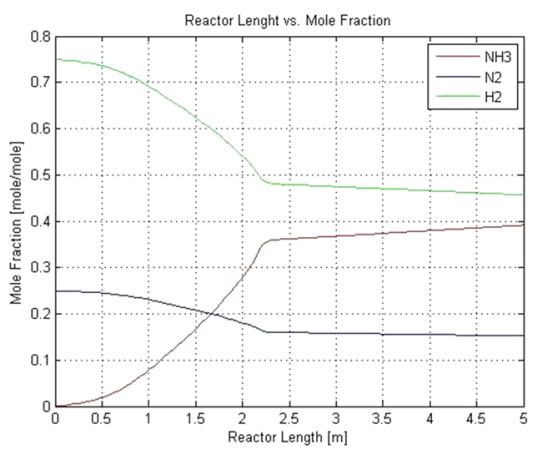

b

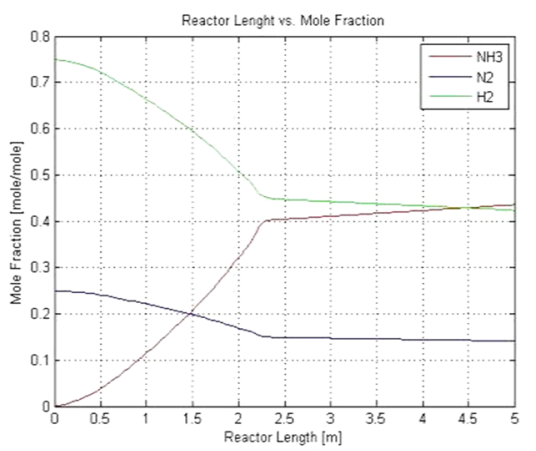

C

Fig. 8 Corresponding reaction extent profiles at the synthesis for three different pressure values $\mathbf{a} 50 \mathrm{bar}$, b $60 \mathrm{bar}, \mathbf{c} 70$ bar and constant mass flow $40 \mathrm{~g} / \mathrm{s}$ bar

higher pressure than suggested for maximum ammonia production at the synthesis lowers the thermal output of the system.

\section{List of symbols}

$Q_{\text {rad,cavity: irradiance on the cavity receiver }(W) ;} \varepsilon_{\text {eff: }}$ effective emissivity; $A_{a p}$ : receiver's aperture area $\left(\mathrm{m}^{2}\right)$; $E$ : infrared energy $(\mathrm{W})$; $\sigma$ : Stefan-Boltzmann constant; $T_{a b}$ : absorbed temperature $\left({ }^{\circ} \mathrm{C}\right) ; T_{\infty}$ : ambient temperature $\left({ }^{\circ} \mathrm{C}\right) ; \varepsilon$ : emissivity; $A_{a b}$ : receiver's absorbed area $\left(\mathrm{m}^{2}\right)$; $q$ : heat flux per unit $\left(\mathrm{W} / \mathrm{m}^{2}\right) ; K_{\mathrm{p}}$ : ammonia dissociation equilibrium (bar); $R$ : universal gas constant ( $\mathrm{J} / \mathrm{mol} \mathrm{K})$; $\Delta G_{R}^{O}$ : Gibbs free enthalpy $(\mathrm{k} / \mathrm{mol}) ; v_{i}$ : stoichiometric coefficients of the reactants and products; $H_{i}^{*}$ : conventional enthalpy of the participating species ( $\mathrm{kJ} /$ $\mathrm{mol})$; S: entropy of the participating species $(\mathrm{J} / \mathrm{mol} \mathrm{K})$.

\section{Authors' contributions}

RAA has done all the data analysis and the writing of all the manuscript under the supervision of Prof. MH. Both authors read and approved the final manuscript.

\section{Acknowledgements}

The authors wish to thank the TU Wien University Library for financial support through its Open Access Funding Program.

\section{Competing interests}

The authors declare that they have no competing interests.

Received: 23 January 2016 Accepted: 1 June 2016

Published online: 29 June 2016

\section{References}

Chen, C. \& Aryafar, H. (2015). Ammonia synthesis for producing supercritical steam in the context of solar thermochemical energy storage". In: Proceedings of the ASME 2015 power conference, San Diego, California. Kreetz, H., \& Lovegrove, K. (2002). Exergy analysis of an ammonia synthesis reactor in a solar thermochemical power system. Pergamon (pp. 187-194). Australia: Elsevier.

Luzzi, A., \& Lovegrove, K. (1995). A solar thermochemical power plant using ammonia as an attractive option for greenhouse gas abatement. In: Pergamon. (Vol. 22). (pp. 317-325).

Steinfeld, A., \& Meiers, A. (2004). Solar fuels and materials. In: Encyclopedia of energy (Vol. 5). Amsterdam: Elsevier.

\section{Submit your manuscript to a SpringerOpen ${ }^{\circ}$ journal and benefit from:}

- Convenient online submission

- Rigorous peer review

- Immediate publication on acceptance

- Open access: articles freely available online

- High visibility within the field

- Retaining the copyright to your article

Submit your next manuscript at $\boldsymbol{\nabla}$ springeropen.com 